\title{
Una mirada a la pintura de Fernando de Szyszlo
}

\author{
A look at the painting of \\ Fernando de Szyszlo
}

\author{
Juan Gustavo Cobo (Colombia) \\ Escritor \\ coborda@gmail.com
}

\section{Resumen \\ Este escrito explora la influencia de los mitos prehispánicos en la obra de Fernando De Szyszlo. La fuerza expresiva y mítica de las inquietudes universales que aquejaban a las civilizaciones perdidas de América del Sur, sobreviven en el trabajo del maestro peruano.}

Palabras clave: arte prehispánico, pintura, artistas peruanos, escultura

\begin{abstract}
This paper explores the influence of prehistoric myths in the work of Fernando De Szyszlo's work. The expressive power and mythical universal concerns that plagued the lost civilizations of South America, survive in the work of the Peruvian artist.
\end{abstract}

Keywords: prehispanic art, painting, Peruvian artists, sculpture 


\title{
Una mira a la pintura de Fernando de Szyszlo
}

\section{A look at the painting of Fernando de Szyszlo}

\author{
Juan Gustavo Cobo (Colombia) \\ Escritor \\ coborda@gmail.com
}

¿De qué noche primordial brota esta pintura? ¿En qué oscura energía se nutre para extender ese fondo sombrío sobre el cual asoman, se insinuan o se recortan esas formas hirientes o aguzadas o esos colores, en ocasiones sutiles y delicados o en otras plenos de fosforescencias submarinas o transparencias propias de los espejismos del desierto o quizá de las atmósferas andinas. Pero hay más: la costa, la sierra o la selva del Perú, dos mil años antes de llamarse así, se unirían en peregrinaje hasta el Chavin de Huantar para adorar al ídolo de piedra donde felino, serpiente y pájaro, alucinógenos y sangre, confluían en esos ojos fríos y sus cuatro colmillos cruzados, como recuerda Mario Vargas Llosa, para suplicar protección contra la muerte, los desastres naturales o las guerras tribales. Ya allí escalinatas, terrazas, oratorios, aposentos, túneles, niebla y color se conjugaban en la ceremonia, en el ritual propiciatorio, en el sacrificio, que ahora, no hay duda, la pintura de Fernando de Szyszlo evoca, convoca e invoca solo con la magia de sus pinceles, en esas cartas astronómicas o sensores subterráneos que son sus óleos.

Siglos de piedra, cordilleras andinas, templos del Sol, santuarios de vírgenes, fortalezas inexpugnables ensambladas a mano, el Imperio inca, con su centro en el Cuzco, solo duraría siglo y medio, pero culturas preincas también nutren el imaginario del pintor, llámense nazca o paracas, con sus 
mantos de plumas, de orquestados colores, o esos tejidos de figuras inquietantes y cruel mitología que aún nos sorprenden. Con razón el poeta Emilio Adolfo Westphalen, en una brillante interpretación de la muestra del pintor en 1963 en torno al poema quechua sobre la muerte de Atahualpa, que tradujo, entre otros, J. M. Arguedas, hace ver cómo Szyszlo se sumergió con su lengua ya formado en una abstracción lírica plenamente contemporánea en aquel pasado - su herencia- en la traición y muerte de ese hijo del dios Sol, dios él mismo, donde la pintura se hizo elegiaca para dolerse de un mundo ya sin centro y una naturaleza desquiciada donde el arcoíris es negro, la sangre camina y los ojos son de plomo. "La tierra se niega / A sepultar a su señor / Como si se avergonzara del cadáver de quien la amó".

Una historia de más de diez mil años, donde el Tahuantinsuyo representa apenas unos cien años, ha nutrido a Szyszlo y, en ella, culturas y civilizaciones prehispánicas atraen con sus nombres y sus logros. Desde el mítico Machu Picchu hasta la desolada Cajamarca. Mochicas, chimús, aimaras, nazcas, chancas, puquinas y muchos otros pueblos. Es coherente que Szyszlo haya dedicado páginas inteligentes tanto a la cultura de Chancay como el arte de Paracas, tal como consta en su libro Miradas furtivas. Paracas, que en quechua significa

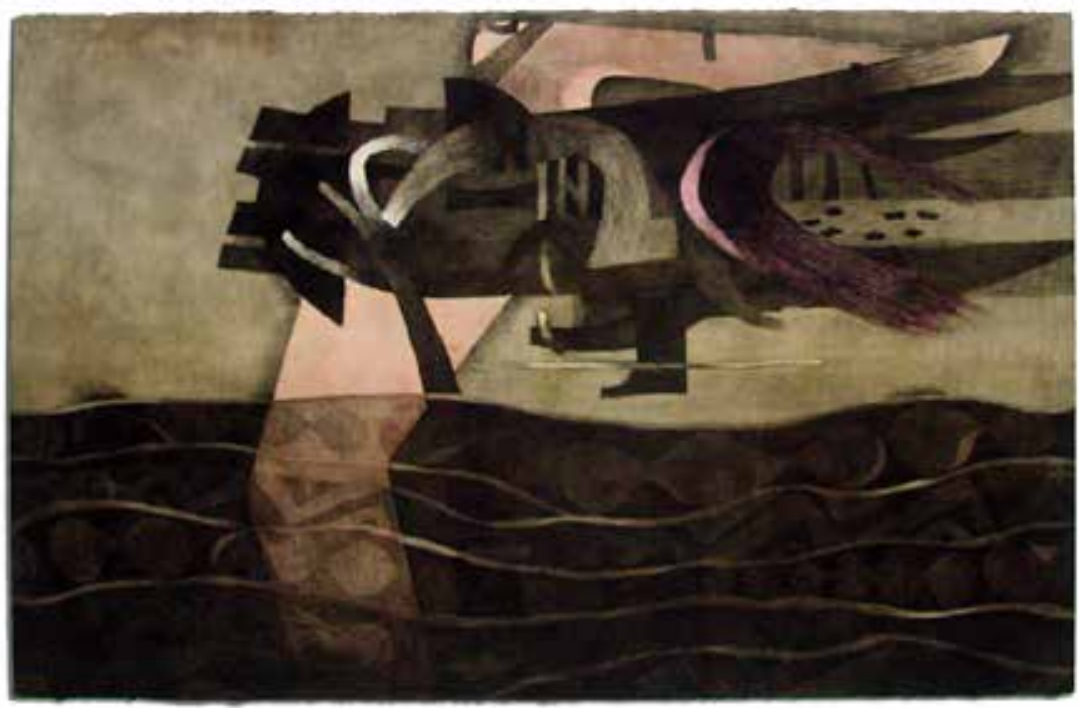

Serie Mar de Lurín, 1994 


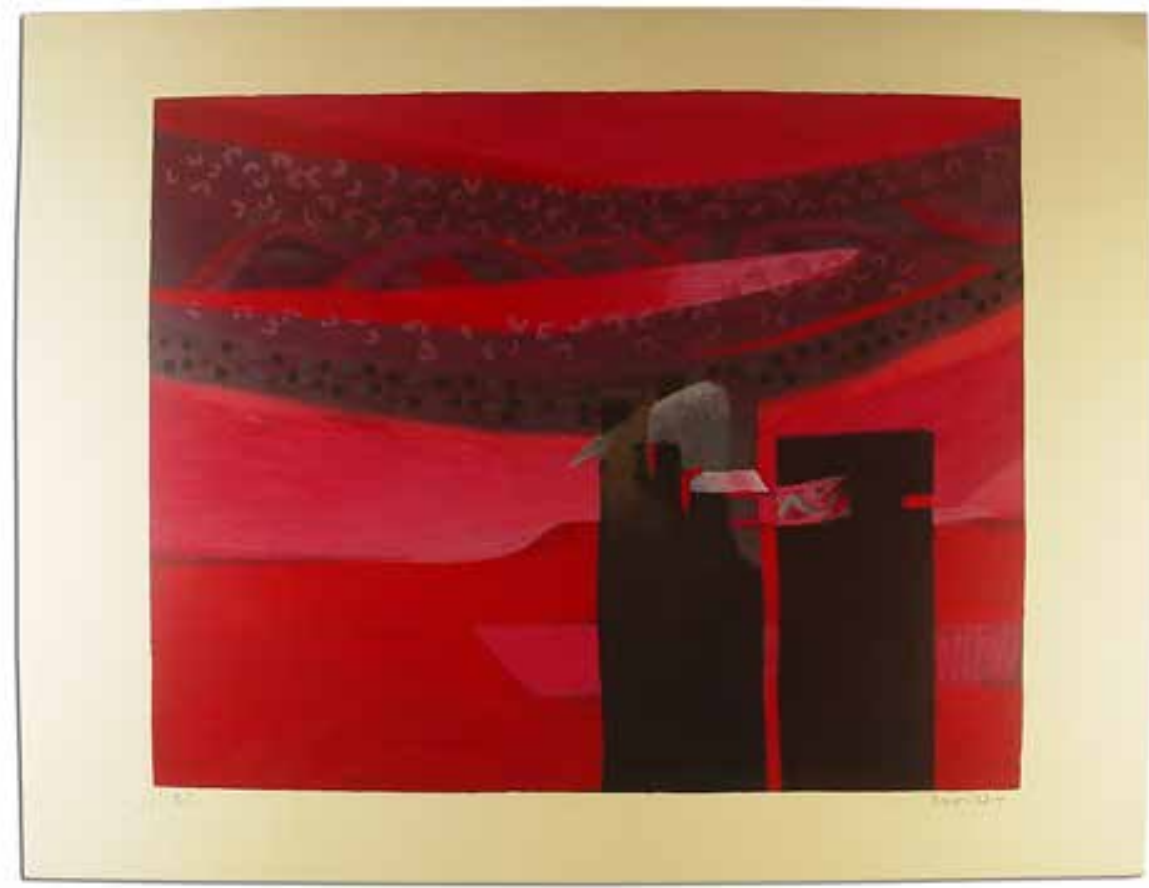

Serie Sol Negro, 1993

'arena que cae como lluvia', lo mismo que Camino a Mendieta, playa del Pacífico, o Mar de Lurín, nos anclan la obra del pintor en sitios concretos y circunstancias específicas. Allí instalará sus noches estrelladas, sus soles negros, sus recintos en penumbra, $y$ como lo dijo Damián Bayón en Pensar con los ojos, "oscuros, densos, trabados de composición” y recorridos por una "luz violeta, negra, fosforecida cuya materia se organiza en amplias pinceladas dirigidas como hierbas que peina un viento abstracto". Más tarde, los cuadros se tornarán verticales, donde "una forma erguida, totémica se eleva agresiva o lenta".

Pero todos sus trabajos, como los que ahora se exponen en la Durban Segnini Gallery, conservan su fuerza expresiva y su carga mítica reinstalando en un mundo desacralizado el temor ancestral ante lo incomprensible - la muerte misma, el fin de civilizaciones - y abriendo, en esas ceremonias soterradas, un cruce implacable de relámpagos de luz y sangre. Como la describió Mario Vargas Llosa, "Una ceremonia que parece a veces de inmolación o sacrificio y que 


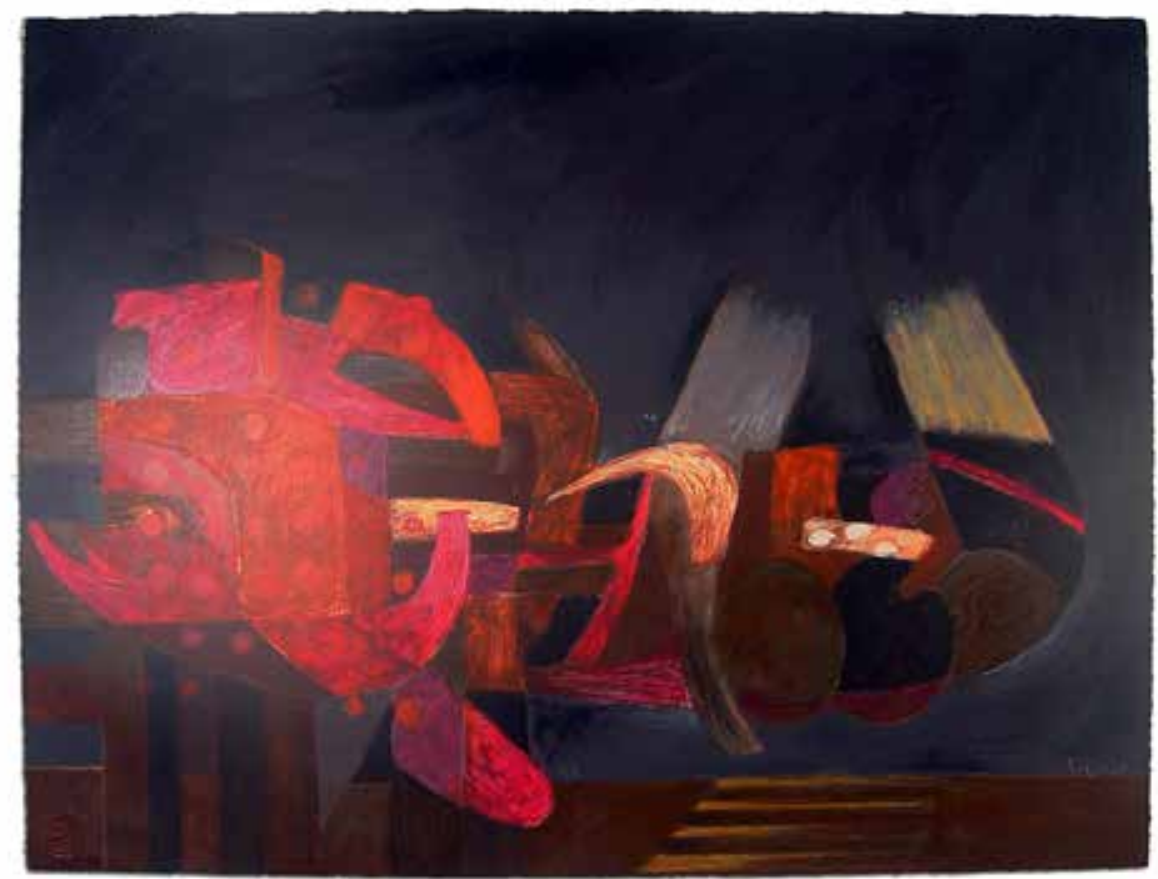

Mesa ritual, 1986

se celebra sobre un ara primitiva. Un rito bárbaro y violento, en el que alguien se desangra, se desintegra, entrega y también, acaso, goza. Algo, en todo caso, que no es inteligible, que hay que llegar a aprehender por la vía tortuosa de la obsesión, la pesadilla, la visión":

Clarividencias oníricas, que se asoman a las profundidades que exploraron sus poetas cercanos, el hilo negro de Vallejo, la incandescencia del deseo en César Moro, el pasajero de la habitación 23 que exaltó
Enrique Molina - y que nos atraen e intrigan - tratando de apoderarnos de su enigma reconocible pero cifrado en el idioma secreto de la más alta pintura. Que dice y, la vez, calla. Aquella que Octavio Paz, en 1959 ya señaló al hablar de un Szyszlo "más dueño de sí, más libre y osado, pero que sigue siendo el mismo: difícil, austero, violencia y lirismo a un tiempo".

Tenemos así un pasado que incita con su peso milenario y una acción contemporánea que lo revive y 
expone a la vista. Que también conmina al espectador a participar de esa fiesta que es a la vez un duelo. Espesor de una materia oleaginosa, transparencias y veladuras, redondeles o signos, que nos atrapan en su decuso, en su lento desplazamiento por la mente o la retina. Inmersión en la materia prima. En el volcánico fuego primordial y su ignición súbita.

Asombro, perplejidad, sigilo, enunciación que calla y claridad enmascarada en los días de ceniza previos al carnaval, a las fiestas y romerías de esos trajes deslumbrantes y abigarrados en sus collares de oro y plata, en sus suntuosos encajes, en la gravedad acompasada de su transcurrir que vuelve cada año, para así abolir el tiempo y mantener viva la tradición. Del barro popular a la paleta nutrida en Tiziano y el claroscuro.

Pintura feliz en su despliegue y agónica en sus postrimerías, Szyszlo se mantiene en su sitio, ya conquistado. Resiste y perdura y vuelve a luchar, ante cada nueva tela, para que los colores - rojo, violeta, azules, verdes, marrones y amarillos- canten y resplandezcan antes de que el sol vuelva a caer o la luna se esfume en el alba límpida. Porque, en realidad, el negro es quien domina.

Sus formas son cuerpos libres de entrelazarse y confundirse o de armarse - dientes, cuñas, espinas- en épicas batallas contra ellas mismas. Pero atrás el espacio se dilata y el horizonte traza con nitidez sus límites en franjas que evolucionan y sufren metamorfosis de pictórica densidad o de levitación abisal. Pero hay algo más alto y trascendente que nosotros mismos. Lo numinoso y terrible de que habló Rilke, o la dorada caverna que talló Rembrandt como un templo en la penumbra para venerar lo inaccesible. Pero este espacio es americano, en la vastedad de la naturaleza -océano, cordillera- o esas celdas claustrales, en fría piedra, que nos encierran con nosotros mismos y nuestros fantasmas de vieja data.

Todo ello proveniente de un país consagrado al sol, como escribió César Moro, "en la costa fertil en culturas mágicas, bajo el vuelo majestuoso del divino pelícano tutelar". De ese Perú, de claridades vueltas sombras tangibles, donde Fernando de Szyszlo ha hecho más grávida la luz del misterio. Ese espacio, por cierto ilusorio, donde por fin podemos vivir. 


\section{Referencias bibliográficas}

Ashton, D. (2003). Szyszlo. Barcelona: Polígrafa.

Bayón, D. (1993). Pensar con los ojos (2.a ed.). México: Fondo de Cultura Económica.

Cobo Borda, J. G. (2009). Fernando de Szyszlo: un signo americano. Lima: Galeria Forum.

Oviedo, J. M. (2014). Archivo personal. Lima: Lapix Editores.

Paz, O. (1967). Corriente alterna. México: Siglo XXI.
Salazar Bondy, S. (1990). Una voz libre en el caos. Lima: Jorge Campadónica Editor.

Szyszlo, F. de (2012). Miradas furtivas. Antología de textos, 1955-2012 (2. ${ }^{\mathrm{a}}$ ed.). Lima: Fondo de Cultura Económica.

Vargas Llosa, M. (2006). Diccionario del amante de América Latina. Barcelona: Paidós.

Westphalen, E. A. 81996). Escritos varios sobre arte y poesía. Lima: Fondo de Cultura. 
- Una mira a la pintura de Fernando de Szyszlo - Juan Gustavo Cobo

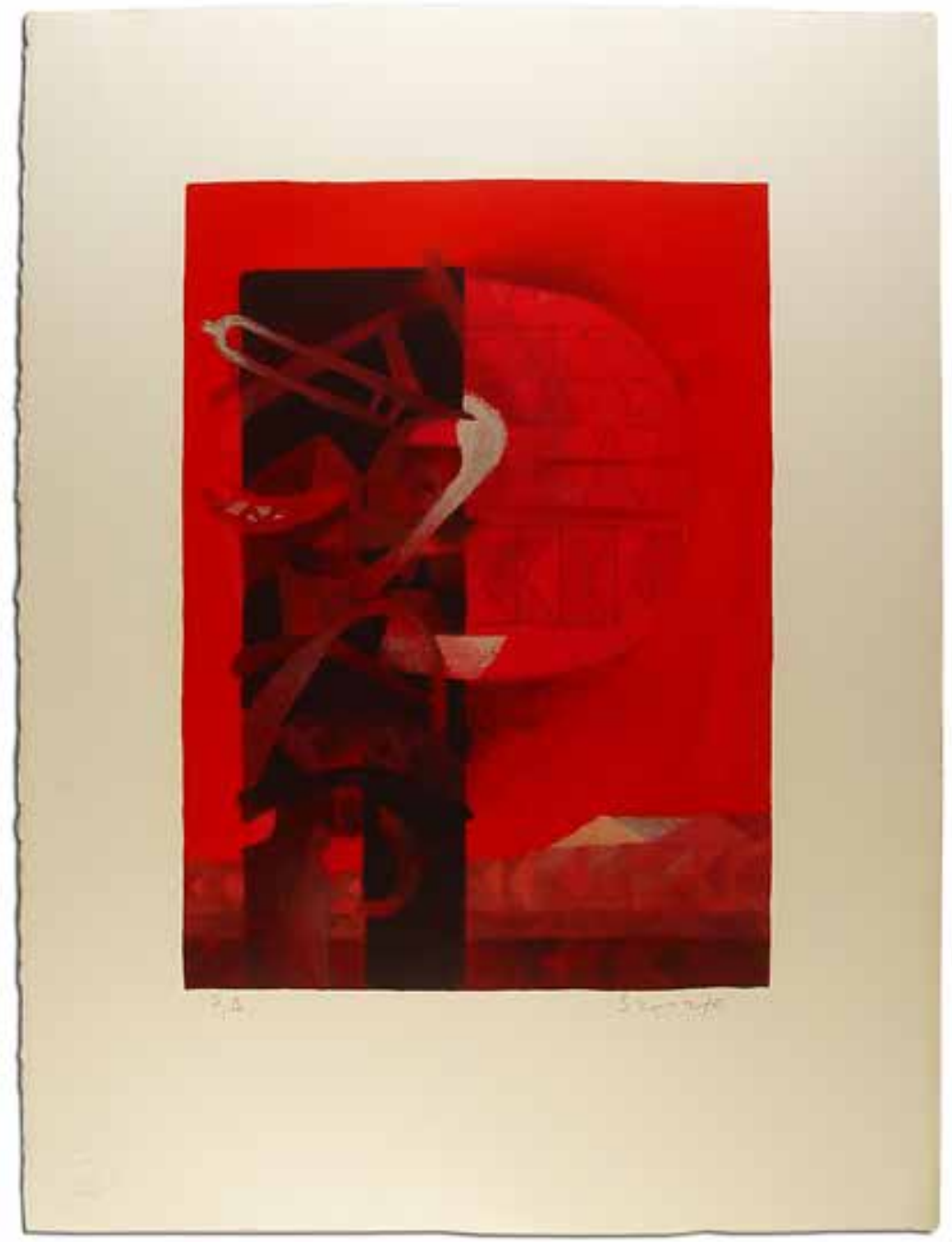

Serie Sol Negro, 1996 